\title{
Avaliação de Comunicabilidade em Rede Social Online para Apoio à Formação Continuada de Professores da Educação Inclusiva: uma Visão Orientada a Valores
}

\author{
Maíra Codo Canal $^{1}$, Roberto Pereira ${ }^{1}$ \\ ${ }^{1}$ Departamento de Informática - Universidade Federal do Paraná (UFPR) \\ Caixa Postal 19.081 - 81.531-980 - Curitiba - PR - Brasil \\ mairapdn@gmail.com, rpereira@inf.ufpr.br
}

\begin{abstract}
This paper presents a communicability evaluation in an Online Social Networks (OSN) designed to support the continuing education of inclusive special education teachers in Brazil. Results point to communication failures that may hinder or even impede user interaction with RSO, and which, discussed by a value-oriented view, can trigger both negative consequences in formal aspects of teaching and learning of those involved, as well as in life impact of end users and other stakeholders.
\end{abstract}

Resumo. Este artigo apresenta uma avaliação de comunicabilidade em uma Rede Social Online (RSO) projetada para apoiar a formação continuada de professores da educação especial inclusiva no Brasil. Resultados apontam falhas de comunicação que podem dificultar ou até mesmo impedir a interação do usuário com a RSO, e que, discutidos por uma visão orientada a valores, podem desencadear tanto conseqüencias negativas em aspectos formais de ensino e aprendizagem dos envolvidos, como também na vida das pessoas, impactando os usuários finais e outras partes interessadas.

\section{Introdução}

RSO são realidade no contexto educacional. De acordo com Johnson et al. (2014), os aspectos em destaque do uso de RSO associadas à educação são a facilidade na comunicação, a familiaridade com a tecnologia e o apoio na troca de conteúdos.

Com o intuito de preencher a falta de apoio para à formação continuada de professores do Atendimento Educacional Especializado (AEE) ${ }^{1}$, foi elaborado o sistema Todos Nós em Rede (TNR) ${ }^{2}$, que possui como objetivo disponibilizar aos professores um ambiente para que possam se comunicar e estabelecer dinâmicas de trabalho. Entretanto, o sistema tem falhado em atender seus objetivos e assim não estabelecendo uma dinâmica continuada de estudos sobre educação inclusiva. Portanto, é necessário investigar o design e avaliação do TNR, para que assim os objetivos da rede não sejam prejudicados por conta de barreiras que possam existir.

Pereira et al. (2013) indicam a necessidade de se considerar uma visão orientada a valores no projeto de tecnologias educacionais. Para colocar em prática essa visão, os autores sugerem que é necessário não só conhecer os usuários finais do sistema, mas também as partes interessadas, como suas expectativas, necessidades, limitações, e todo o ecossistema no qual a comunidade escolar vive e está inserida. Nessa direção, valores

\footnotetext{
${ }^{1}$ Portal MEC. http://portal.mec.gov.br/index.php?option=com_docman\&view=download\&alias=428diretrizes-publicacao\&Itemid=30192

${ }^{2}$ Todos Nós em Rede. https://tnr.nied.unicamp.br. Último acesso em 11/07/2018
} 
VII Congresso Brasileiro de Informática na Educação (CBIE 2018)

Anais do XXIX Simpósio Brasileiro de Informática na Educação (SBIE 2018)

podem influenciar a aceitação de uma RSO em contexto escolar, e na maneira como essa rede é percebida, compreendida e usada. Portanto, negligenciar valores no projeto de RSO pode resultar em uma rede que não faça sentido para os usuários, que não atenda às expectativas das partes interessadas, e que possam desencadear impactos não desejáveis, difíceis de prever e reverter, no contexto social em que a RSO é utilizada.

Com fundamentos na Semiótica [Peirce 1955] e na Teoria de Affordances [Gibson 1979], Pereira et al. (2015) sugerem que valor é aquilo que denota importância para alguém em algum respeito ou capacidade. Nessa direção, adotar uma visão orientada a valores no design e avaliação de RSO é considerar não somente os aspectos da interação dos usuários com a RSO, mas também, as demais relações existentes entre a pessoa e o mundo em que ela vive. Desse modo, valores transcendem aspectos de usabilidade, acessibilidade, privacidade, autonomia, entre outros.

Avaliar o modo como valores são promovidos ou comunicados em RSO ainda é um desafio para a área de Interação Humano-Computador (IHC), pois não há método de avaliação orientado a valores bem estabelecido que apoie os avaliadores. Assumindo que valores podem ser comunicados pelos projetistas aos usuários por meio da interface de uma RSO, este trabalho realizou uma avaliação do TNR por meio do Método de Inspeção Semiótica (MIS) [de Souza 2005]. Os resultados apontam rupturas de comunicação nos recursos de compartilhamento, busca, ajuda e feedback, e ainda oferecem insumos para discutir como o MIS pode ser adaptado para dar suporte a avaliadores para investigar valores em RSO.

\section{Método e Resultados}

O MIS foi aplicado por 3 especialistas em IHC para avaliar a comunicabilidade no TNR e, como consequência, verificar o potencial do método para apoiar uma avaliação orientada a valores. Os cenários elaborados para a realização da avaliação foram a interação de professores com o TNR, com os objetivos de consultar e de compartilhar materiais e experiências sobre os desafios vivenciados pelos professores. Os avaliadores se colocaram no perfil de professores do AEE e com o apoio do TNR, realizaram algumas tarefas. Cada avaliação individual durou cerca de 45 minutos. Em seguida, os avaliadores consolidaram a avaliação. Alguns dados estão apresentados de acordo com as tarefas, juntamente com os problemas e soluções sugeridas pelos avaliadores.

T1. Compartilhar material de apoio. Ao realizar a T1, os 3 avaliadores relataram que ficaram confusos devido ao fato de existir na interface principal da RSO uma aba denominada material de apoio e outra com o rótulo de compartilhar (ver Figura 1). Os 3 avaliadores relataram que tiveram que descobrir em qual aba deveriam clicar para compartilhar o material experimentando as duas opções disponíveis para saber qual opção levaria a possibilidade de compartilhar o material. Uma possível solução apontada pelos avaliadores é que poderia haver na interface apenas uma aba com o rótulo "Material de apoio", e dentro dessa opção haver outra para o compartilhamento, ou ficar somente a aba "Compartilhar" na interface.

Ainda na $T 1$, os avaliadores relataram que também ficaram confusos com as opções disponíveis para selecionar qual o tipo de material seria compartilhado. $\mathrm{Na}$ interface referente a compartilhar material, existem algumas opções definidas com rótulos de arquivo, adicionar novo arquivo, imagem, vídeo/áudio e arquivo multimídia. Os avaliadores ainda afirmaram que professores que não possuem conhecimento em computação podem se sentir ainda mais confusos sobre qual opção escolher para compartilhar o material. Os avaliadores relataram que os professores podem não 
VII Congresso Brasileiro de Informática na Educação (CBIE 2018)

Anais do XXIX Simpósio Brasileiro de Informática na Educação (SBIE 2018)

entender os significados das siglas dos tipos de arquivos informados na interface para o usuário (e.g., txt, docx, xls, ods, odp). Os avaliadores sugeriram que poderia haver apenas uma opção para compartilhar o tipo de arquivo, e apenas informações referentes ao tipo de arquivo que podem ser compartilhados (e.g., texto, imagem, vídeo); e ainda que as informações sobre o tipo de arquivo não estivessem na interface. Dos 3 avaliadores, apenas 1 ao realizar a $T 1$, levantou a possibilidade de haver recurso de privacidade sobre o compartilhamento, pois, segundo esse avaliador, alguns professores podem se sentir constrangidos em compartilhar algo que todos tenham acesso.

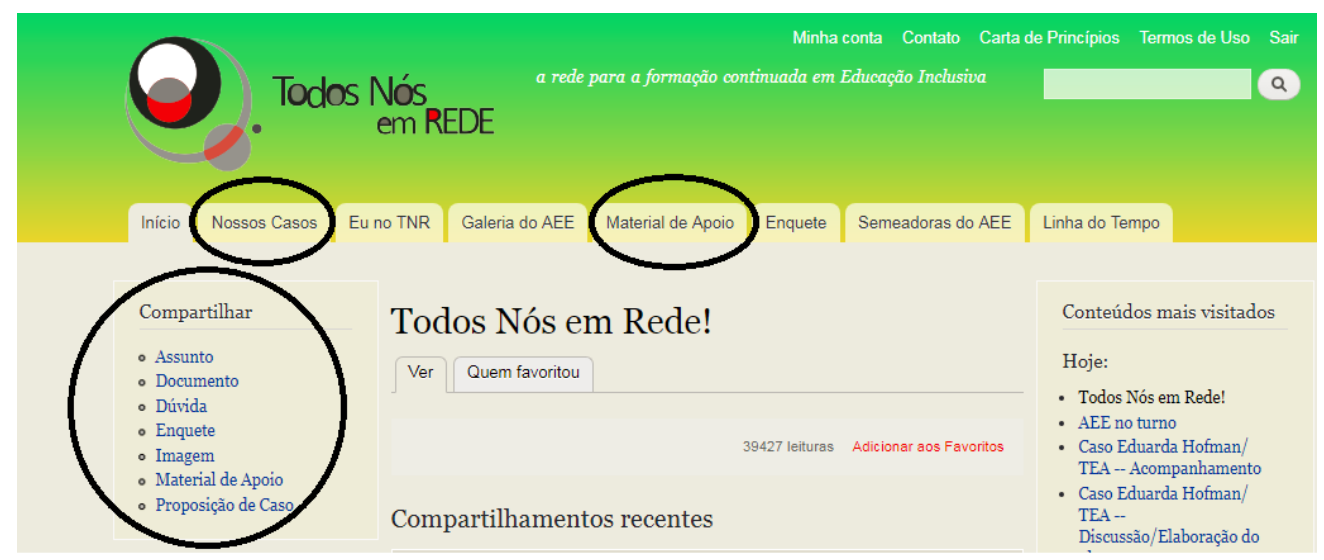

Figura 1. Rótulos das abas de material de apoio e de compartilhamento.

Os 3 avaliadores também identificaram que, ao compartilhar um material, as opções disponíveis são um botão de rótulo salvar e o outro de pré-visualizar. Os avaliadores ficaram confusos em qual opção clicar para compartilhar o material e sugeriram uma opção de compartilhar para disponibilizar o material. Ao clicar na opção pré-visualizar, aparece a seguinte mensagem como feedback: " (chamada (um resumo do seu post) será mostrado quando ele for promovido para a página inicial ou exportado no formato RSS)". Os avaliadores acreditam que os professores podem encontrar dificuldades de entender essa mensagem. Não há feedback sobre se o material foi compartilhado, o que pode tornar ainda mais difícil para o usuário se situar quanto ao estado do sistema e as consequências de suas próprias ações.

T2. Compartilhar casos. Ao inspecionar as interfaces na $T 2$, os avaliadores identificaram que o mesmo problema com a confusão dos rótulos persistia conforme na T1. As abas com rótulos "Compartilhar" e "Nossos Casos" deixaram os avaliadores confusos sobre em qual opção deveriam clicar para compartilhar casos (ver Figura 1). Os avaliadores sugeriram que apenas uma aba fosse mantida para não confundir o usuário. Os problemas com as opções do tipo de arquivo a ser compartilhado também ocorreu com a T2. Os avaliadores sugeriram a mesma solução já informada para a $T 1$. O mesmo avaliador que identificou a falta de recursos de privacidade na $T 1$, também observou que o sistema não oferece recurso de privacidade na $T 2$.

T3. Consultar material de apoio. Uma dificuldade apontada pelos avaliadores ao executarem a $T 3$ foi na opção de selecionar material desejado para consulta. A interface apresenta uma lista de itens que se referem ao tema de interesse que o usuário deseja que sejam retornados os materiais da busca. Nessa interface, além do item de interesse a ser selecionado pelo usuário, existe uma lista com dois itens com rótulos de crescente e decrescente. Os avaliadores relataram que se sentiram confusos sobre o real significado da classificação com rótulos de crescente e decrescente e sugeriram rótulos mais precisos de ordenação, que realmente tivessem algum significado para os usuários. Além disso, sugeriram que descrições fossem colocadas abaixo das opções para 
VII Congresso Brasileiro de Informática na Educação (CBIE 2018)

Anais do XXIX Simpósio Brasileiro de Informática na Educação (SBIE 2018)

informar ao usuário o seu real significado. Os avaliadores também identificaram que ao efetuar uma busca, não era possível observar pelo feedback qual a ordenação dos materiais apresentados. Ao realizar a T3, os avaliadores não encontraram recurso de ajuda para usar a RSO, pois gostariam de saber como usar os recursos de ordenação.

T4 Consultar casos. Ao inspecionar as interfaces para executar a T4, os avaliadores observaram que os casos eram apresentados ao usuário sem nenhuma hierarquia específica. Os avaliadores ficaram confusos ao identificar qual a ordem estabelecida pelo projetista sobre a apresentação dos casos na interface na busca dos casos. Os avaliadores ficaram confusos com os rótulos de ultima atualização e último comentário. Com o intuito de solucionar essa ruptura de comunicação ao realizar a $T 4$, os avaliadores sugeriram que apenas um rótulo fosse mantido, neste caso, que o de última atualização fosse mantido e o de último comentário fosse retirado, pois segundo os avaliadores, último comentário faz referência a atualização da postagem.

\section{Discussão}

Além das rupturas de comunicação encontradas, foi possível identificar indícios referentes a valores. $\mathrm{Na}$ inspeção, um avaliador identificou que o TNR não oferece recursos de privacidade no compartilhamento de materiais e de casos, comunicando assim, uma decisão do design para o usuário de que o usuário só pode compartilhar informações na rede que fiquem visíveis para todos. Assim, professores podem compartilhar fotos na rede para acesso de todos, e ainda pode ocorrer o fato de vazamento de fotos em outras redes sociais, afetando a privacidade e a visibilidade de partes interessadas além dos usuários finais, como os estudantes e seus familiares, e ainda ocasionando outras implicações relacionadas ao valor de ética. Pereira Junior et al. (2013) encontraram problemas de comunicabilidade nos recursos de privacidade em RSO e afirmam a necessidade de pesquisas que apoiem os profissionais de IHC a identificar potenciais problemas sociais que podem ser ocasionados pelas rupturas de comunicação, para que possam ser evitados. Ainda no contexto da privacidade, Villela e Prates (2015) também relatam a importância de conscientizar os projetistas sobre os impactos que as decisões de design podem ocasionar aos usuários, como por exemplo sobre a divulgação de informações pessoais nas RSO.

Valores não estão sendo promovidos por meio dos recursos disponibilizados nas interfaces do sistema, como a autonomia, acessibilidade e inclusão por exemplo, pois as rupturas de comunicação encontradas pelos avaliadores podem causar dificuldades ou até impedir o uso da RSO. Do ponto de vista técnico, os problemas de acessibilidade podem impedir a participação de professores que tenham algum tipo de limitação (e.g., física, cognitiva, letramento digital). Do ponto de vista orientado a valores, além das limitações do usuário, se reconhece que a falta de acessibilidade impacta negativamente na autonomia e na afetividade de uma pessoa, prejudica o pleno exercício de suas atividades, reforça a exclusão, e impede que os benefícios do engajamento e da participação de todos se estendam à comunidade escolar, aos alunos e suas famílias.

Adotando uma visão orientada a valores, é possível identificar que os estudantes podem ser afetados com relação a aspectos econômicos, pois caso haja problemas de aspectos formais com sua aprendizagem, eles podem encontrar dificuldades e até ficarem impedidos de ingressar no ensino superior público ou a entrar no mercado de trabalho. Por conta desses problemas, os pais desses estudantes também podem ser afetados, já que alguns deles lutam pelos direitos de igualdade dos filhos ao ensino. Contudo, no caso do MIS é necessário apoiar explicitamente o avaliador para que ele 
VII Congresso Brasileiro de Informática na Educação (CBIE 2018)

Anais do XXIX Simpósio Brasileiro de Informática na Educação (SBIE 2018)

possa investigar a comunicação de valores por meio das suas etapas: preparação, coleta e interpretação dos dados, consolidação e relato dos resultados. Sem apoio explícito nas etapas do método de avaliação aplicado, a consideração de valores continuará a depender da habilidade do avaliador e do seu entendimento prévio sobre a questão.

\section{Conclusões e Trabalhos Futuros}

Com o uso do MIS foi possível identificar que designers comunicam valores aos usuários por meio das interfaces da RSO. Entretanto, é necessário guiar o avaliador para que ele identifique na etapa de preparação, quais valores dos usuários e de demais partes interessadas devem ser comunicados pelos designers aos usuários. $\mathrm{Na}$ etapa de coleta e interpretação dos dados, é preciso a inserção de artefatos de apoio ao avaliador para que ele seja capaz de identificar se o modo como os valores estão sendo comunicados podem ocasionar consequências negativas na vida das pessoas. As etapas seguintes devem ser direcionadas ao relato dos resultados com base nas negligências encontradas com valores no projeto de RSO na educação.

Trabalhos futuros incluem um método de avaliação em IHC que seja informado por uma visão orientada a valores para a avaliação de RSO em contexto educacional. Com esse método, espera-se ser possível investigar se valores de usuários finais do sistema e de demais partes interessadas estão sendo comunicados e, ainda, a maneira como esses valores estão sendo comunicados pelo designer aos usuários.

\section{Agradecimentos}

O presente trabalho foi realizado com apoio da Coordenação de Aperfeiçoamento de Pessoal de Nível Superior - Brasil (CAPES) - Código de Financiamento 001.

\section{Referências}

de Souza, C. S. (2005). "The semiotic engineering of human-computer interaction". MIT Press, Cambridge MA, U.K.

Gibson, J. (1979). “The Ecological Approach to Visual Perception”. Houghton Mifflin Harcourt (HMH), Boston.

Johnson, L. Adams Becker, S. Estrada, V. e Freeman, A. (2014). "NMC Horizon Report: Higher Education Edition". Austin, Texas: The New Media Consortium.

Peirce, C.S. (1955). "Philosophical Writings of Pierce". Editor by J. Bachler, New York, Dover Publications.

Pereira, R. Baranauskas, M. C. C. e Liu, K. (2015). "The Value of Values for HCI: an informed discussion beyond philosophy". In XIV Simpósio Brasileiro de Fatores Humanos em Sistemas Computacionais (IHC). 430-439.

Pereira, R. Hayashi, E.C.S. e Baranauskas, M.C.C. (2013) "Afeto como um Valor no Design de Tecnologias Educacionais: frameworks e discussões informadas". Anais do XXIV Simpósio Brasileiro de Informática na Educação (SBIE), pp.748-757.

Pereira Junior, M. Villela, M. L. B, Rocha, E. C. F. e Prates, R. O. (2013) "O Navegar Impreciso ? A Privacidade no Facebook Vivenciada por seus Usuários". In IX Simpósio Brasileiro de Sistemas de Informação (SBSI). Anais do IX SBSI.

Villela, M. L. B. e Prates, R. O. (2015) "Supporting Designers in Modeling Privacy for Social Network Sites”. In XIV Simpósio Brasileiro de Fatores Humanos em Sistemas Computacionais (IHC). 